\title{
Blood spot glucocorticoid concentrations in ill preterm infants
}

\author{
D HUGHES, J F MURPHY, J DYAS, J A ROBINSON, D RIAD-FAHMY, AND I A HUGHES \\ Department of Child Health and Tenovus Institute, University of Wales College of Medicine, Cardiff
}

SUMmaRY The adrenocortical response to stress was studied longitudinally in 10 ill preterm infants using measurements of cortisol and $170 \mathrm{H}$-progesterone concentrations in filter paper blood spots. Mean cortisol and $170 \mathrm{H}$-progesterone concentrations reached a peak of $2200 \mathrm{nmol} / \mathrm{l}$ and $65 \mathrm{nmol} / 1$, respectively, between the third and fifth days of life. These concentrations far exceeded those observed in older children and adults subjected to stress as a result of surgery. Further pulses of endogenous cortisol production of $4000 \mathrm{nmol} / \mathrm{l}$ or more occurred in association with clinical complications such as intraventricular haemorrhage. These results indicate that infants undergoing intensive care are unduly stressed. Consideration should be given to providing enough sedation and appropriate analgesia for ill preterm infants during painful procedures such as insertion of venous cannulae and arterial puncture.

Increased plasma concentrations of $170 \mathrm{H}-$ progesterone (17P) and cortisol in ill preterm infants have previously been reported. ${ }^{12}$ These observations, which indicated a presumed stress response, were based only on single random measurements of plasma steroid concentrations. Little is known about the magnitude and duration of the adrenocortical response to stress in the newborn. A study of ill infants during the first three days after birth by Gutai et al showed that there was no significant increase in plasma cortisol concentrations. Most of the infants studied were not unduly stressed when assessed by clinical criteria. ${ }^{3}$ In a study of ill preterm infants with hyaline membrane disease,${ }^{4}$ however, the peak plasma glucocorticoid response achieved was related to the severity of respiratory distress.

Studies, in which serial measurements of plasma steroid concentrations in ill preterm infants have been made, have been limited by the difficulty of collecting venous samples from small infants. A steroid assay, which uses whole blood spotted on to filter paper, has recently been developed however, ${ }^{5-7}$ and this technique, which requires only a small volume of blood, has been used to obtain longitudinal data on 17P and cortisol concentrations as an index of the adrenocortical response to stress in a group of ill preterm infants.

\section{Patients and methods}

Ten preterm patients were studied longitudinally for the first 13 days of life. All were very ill and required assisted ventilation for severe hyaline membrane disease. Table 1 presents their clinical details. Gestational age was assessed by the method of Ballard et al. ${ }^{8}$ Arterial catheters (umbilical or radial) were inserted shortly after birth for measurements of blood gas and invasive blood pressure monitoring. When an arterial sample was collected additional drops were spotted on to a Guthrie card sufficient to fill completely four $10 \mathrm{~mm}$ circles. The date and time of each sample collection was recorded for each infant. The filter paper card was left to dry at room temperature before being sent to the laboratory for analysis. In five of the infants blood spots were obtained at about six hourly intervals for three to five days.

Blood spot 17P concentrations were determined by a specific radioimmunoassay. ${ }^{7} \mathrm{~A}$ similar method was used to determine cortisol concentrations in blood spots, but solvent extraction was not required. Briefly, $50 \mu \mathrm{l}$ of ethanol followed by $200 \mu \mathrm{l}$ of phosphate buffer solution were added to each $6 \mathrm{~mm}$ disc punched out of a blood spot. ${ }^{125}$ I-labelled cortisol and an anticortisol serum that had been coupled to magnetisable cellulose were added to 
Table 1 Clinical details of 10 infants studied

\begin{tabular}{lllll}
\hline Case No & Sex & Birth weight $(g)$ & Gestation (weeks) & Clinical problems \\
\hline 1 & $\mathrm{~F}$ & 1860 & 32 & HMD, IVH; died at 14 days \\
2 & $\mathrm{~F}$ & 805 & 28 & HMD, PDA; died at 6 weeks \\
3 & $\mathrm{M}$ & 9700 & 25 & HMD, IVH, NEC \\
4 & $\mathrm{M}$ & 30 & HMD, IVH, PDA \\
5 & $\mathrm{M}$ & 1850 & 32 & HMD, IVH, ARF \\
6 & $\mathrm{~F}$ & 1630 & 31 & HMD, PDA, ARF, pneumothorax \\
7 & $\mathrm{M}$ & 780 & 25 & HMD, PDA, NEC; died at 22 days \\
8 & $\mathrm{M}$ & 1140 & 31 & HMD, IVH, DIC, ARF \\
9 & $\mathrm{M}$ & 850 & HMD, IVH, ARF; died at 15 days \\
10 & $\mathrm{M}$ & 1485 & $28 \cdot 8$ & \\
\hline \multirow{2}{*}{ Mean } & & 1313 & $24-32$ & \\
Range & & $805-1860$ & & \\
\hline
\end{tabular}

$\mathrm{HMD}=$ hyaline membrane disease; $\mathrm{IVH}=$ intraventricular haemorrhage; $\mathrm{PDA}=$ patent ductus arteriosus; $\mathrm{NEC}=$ necrotising enterocolitis; $A R F=$ acute renal failure; $D I C=$ disseminated intravascular coagulation.

$100 \mu \mathrm{l}$ of the ethanol-buffer solution and the mixture incubated for one hour. Antibody bound and free steroids were separated using a magnetic tray and the radioactivity was counted in a multiwell gamma counter. Unknown sample concentrations were interpolated from the dose-response curve. Blood spot cortisol and 17P values were converted to the equivalent concentration in plasma based on the assumption that each disc contained $4.5 \mu \mathrm{l}$ plasma. ${ }^{7}$ For both assays the intra- and interassay coefficients of variation did not exceed $7.0 \%$ and $11.5 \%$, respectively. Table 2 summarises the characteristics of the blood spot assays. Data were calculated as mean (SEM) and compared using Student's unpaired $t$ test. In those infants from whom more than one sample was collected each day the mean steroid concentration was used to determine mean values for the total group of 10 infants studied.

\section{Results}

Fig 1 shows the mean (SEM) blood spot cortisol

Table 2 Relevant characteristics of blood spot radioimmunoassays

\begin{tabular}{lllll}
\hline Characteristic & \multicolumn{2}{l}{ Steroid } & & \\
\cline { 2 - 4 } & $170 \mathrm{H}$-progesterone & Cortisol & \\
\hline Sensitivity & $1.0 \mathrm{nmol} / \mathrm{l}$ & $28 \mathrm{nmol} / \mathrm{l}$ & \\
Range & $1.0-550 \mathrm{nmol} / \mathrm{l}$ & $28-2450 \mathrm{nmol} / \mathrm{l}$ & \\
Cross reactivity & & & \\
$(\%):$ & $170 \mathrm{H}$-pregnenolone & 7.4 & 11 -deoxycortisol & 28 \\
& Progesterone & 5.9 & Cortisone & 23 \\
& 21-deoxycortisol & 1.5 & Corticosterone & 20 \\
& Pregnenolone & 0.3 & Prednisolone & $4 \cdot 7$
\end{tabular}

Cross reactivity $=$ amount of steroid required to displace $50 \%$ binding of labelled $17 \mathrm{P} /$ cortisol at zero binding concentrations determined serially in 10 infants from birth to 13 days of age. The mean cortisol concentration increased more than twofold during the first few days to reach a maximum of about 2000 $\mathrm{nmol} / \mathrm{l}$ between days 3 to 5 . Blood spot cortisol concentrations decreased during the ensuing four days, and thereafter stayed constant over the remainder of the study period. Fig 2 shows the

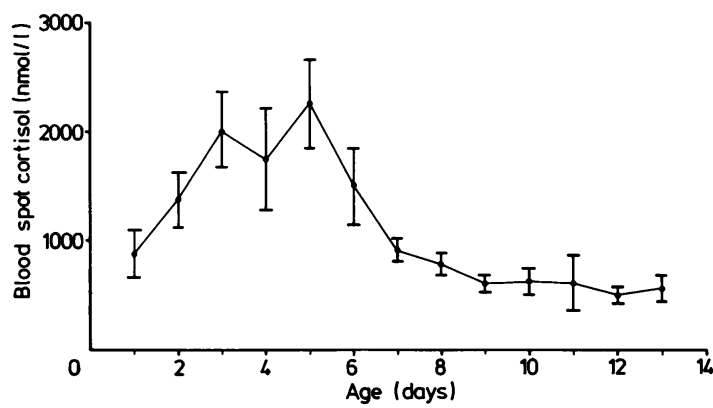

Fig 1 Mean (SEM) blood spot cortisol concentration in ill preterm infants.

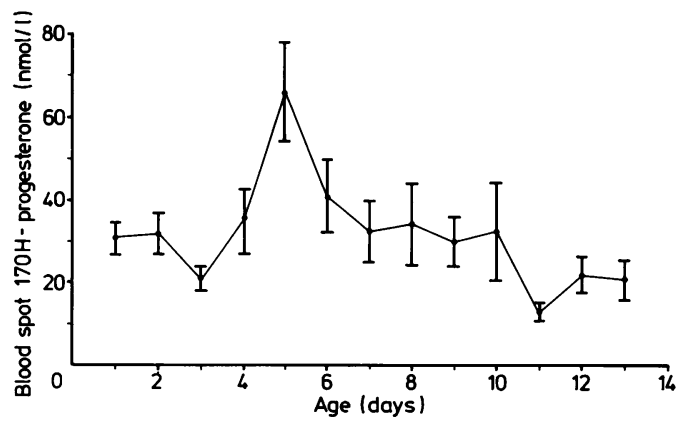

Fig 2 Mean (SEM) blood spot 170H-progesterone concentration in ill preterm infants. 
1016 Hughes, Murphy, Dyas, Robinson, Riad-Fahmy, and Hughes

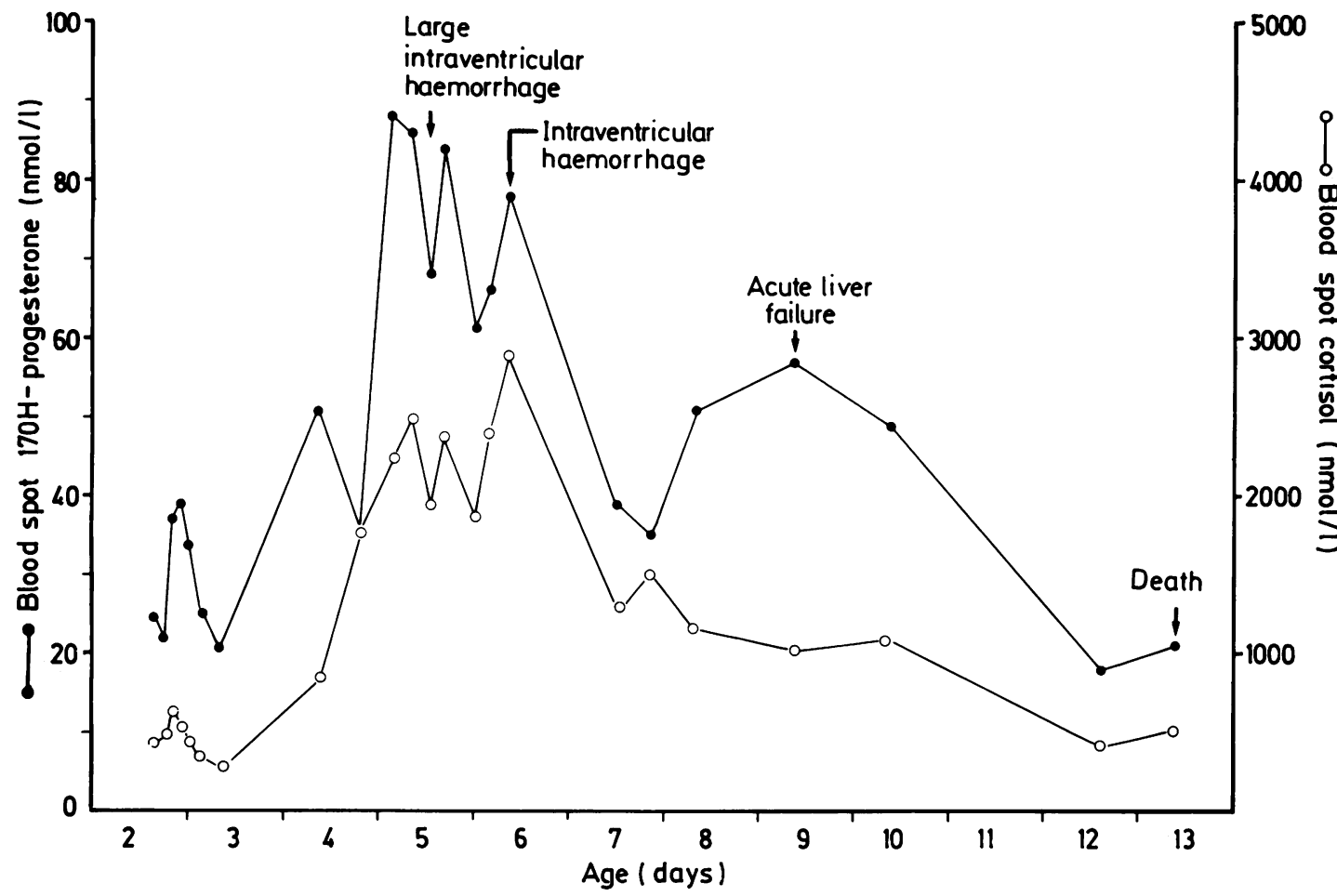

Fig 3 Serial blood spot cortisol and 170H-progesterone concentrations in an ill preterm infant: stressful clinical events (arrows).

pattern of blood spot 17P concentrations measured over the same time period. Peak values were seen on day 5 with a mean $17 \mathrm{P}$ concentration of 65 $\mathrm{nmol} / \mathrm{l}$. The increased blood spot $17 \mathrm{P}$ concentrations in preterm ill infants compared with those measured in healthy full term infants (range $3-18 \mathrm{nmol} / \mathrm{l}$ ) were still evident on day 13.

Fig 3 shows the individual blood spot 17P and cortisol concentrations in one infant who died. The peak cortisol concentration exceeded $4000 \mathrm{nmol} / \mathrm{l}$; this coincided with the development of a large intraventricular haemorrhage shown on cranial ultrasonography. Extension of the blood into the brain parenchyma was accompanied by further pulses in cortisol secretion. The infant subsequently developed hepatic failure and died. Just before death the concentrations of cortisol fell. A similar pattern of secretion was seen in plasma 17P concentrations. Fig 4 shows the individual profiles of cortisol concentrations determined in serial blood spots collected from five infants. There was a large range of values, but most infants had cortisol concentrations consistently above $1000 \mathrm{nmol} / \mathrm{l}$.

\section{Discussion}

Mixed cord blood cortisol concentrations in healthy term infants are relatively high $(800 \mathrm{nmol} / \mathrm{l})$ but fall rapidly within 24 hours of birth to about $270 \mathrm{nmol} / \mathrm{l}^{9}$ The cortisol gradient may be the result of placental transfer of maternal plasma free cortisol, or it may be due to increased fetal adrenal activity because of the stress of delivery. ${ }^{10}$ There is no obvious difference in cortisol concentrations between healthy term and preterm infants during the first 10 days after birth. ${ }^{11}$

The pattern of cortisol secretion in ill preterm infants seems to be quite different. In this study cord blood cortisol concentrations were not measured. Although individual cortisol concentrations varied widely during the first six days after birth, blood spot cortisol concentrations progressively increased reaching a peak on day 3 . They remained constant for two days before decreasing gradually over the remaining eight days of the study. Even the smallest preterm infant seems to be able to secrete large amounts of adrenocortical hormones for a 


\section{Glucocorticoid concentrations in ill infants 1017}

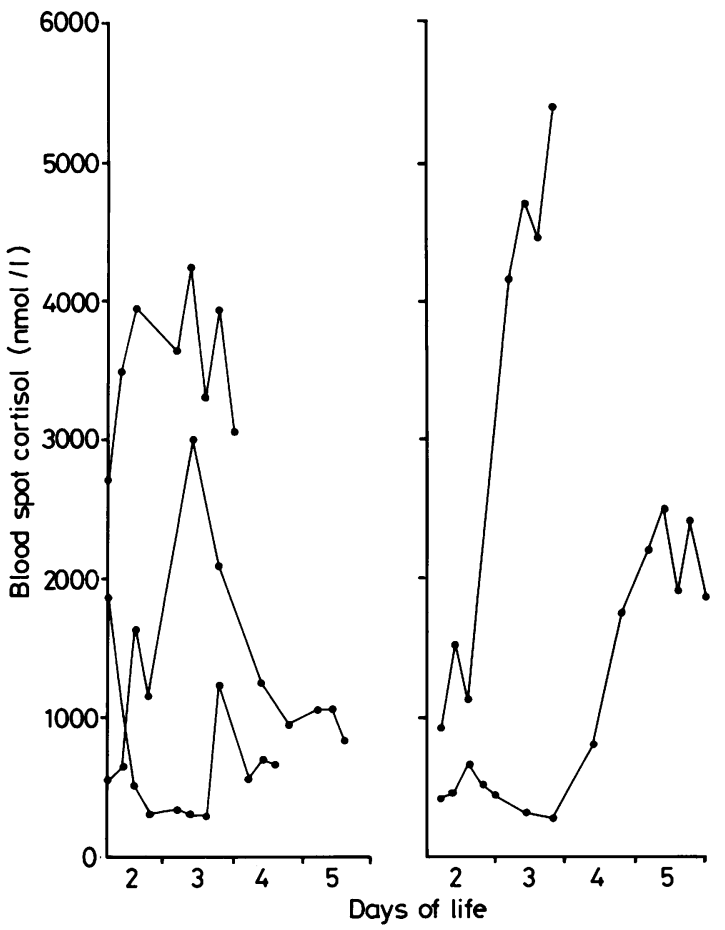

Fig 4 Blood spot cortisol profiles in five ill preterm infants.

protracted period in response to stress. A similar response was observed in concentrations of $17 \mathrm{P}$ in response to stress. Interestingly, peak cortisol and 17P concentrations were delayed until days 3 and 5, respectively, even though the infants were generally most ill during the first 72 hours after birth.

Studies in newborn rats have shown that there is a clearly defined period when rats do not respond to stress. ${ }^{12}$ : This is an interval immediately after birth during which the adrenocortical neonatal response to a variety of stresses is absent. ${ }^{13}$ Corbier and Roffi ${ }^{14}$ showed that in rats the period of absolute unresponsiveness to stress was followed by a period of relative unresponsiveness. The authors proposed that increased concentrations of corticosteroid, the principal glucocorticoid in rats, accumulate in the brain and inhibit the production of corticotrophin releasing factor. Alternatively, it was suggested that the absence of response was the result of a transient defect in adrenocorticosteroid synthesis. This is unlikely in view of the findings of a previous study which showed that ill preterm infants attain adequate concentrations of plasma cortisol if given adrenocorticotrophic hormone $(\mathrm{ACTH}){ }^{2}$ If a similar period of absolute or relative unresponsiveness to stress also occurs in human neonates, this may be important in the early management of the very ill preterm infant.

The results of this study illustrate that small ill preterm infants experience considerable stress while undergoing intensive care. Furthermore, an added clinical complication such as the extension of an intraventricular haemorrhage (fig 3 ) results in a further pulse of endogenous cortisol secretion. The pronounced changes in cortisol concentrations seen over 24 hours (fig 4) indicate that frequent sampling is required to define the period when a surge in adrenocortical activity occurs. Blood spot sampling is ideal for this purpose.

Comparable studies in adults undergoing major and minor operations indicate that mean postoperative plasma cortisol concentrations reach 1080 $\mathrm{nmol} / \mathrm{l}$ and $540 \mathrm{nmol} / \mathrm{l}$, respectively, ${ }^{15}$ values considerably lower than those achieved in ill preterm infants. The neonatal adrenal gland has a remarkable capacity for cortisol production; and Forest reported concentrations as high as $11556 \mathrm{nmol} / \mathrm{l}$ in infants given ACTH $500 \mu \mathrm{g} / \mathrm{m}^{2}$ twice daily for three days. ${ }^{16}$ Newborn puppies subjected to haemorrhagic shock achieved cortisol concentrations up to 2000 $\mathrm{nmol} / \mathrm{l} .{ }^{17}$ It was notable that the highest cortisol concentrations occurred in those puppies that died first. In a study of term infants undergoing cardiac operations with cardiopulmonary bypass, the plasma cortisol concentration increased from 356 $\mathrm{nmol} / \mathrm{l}$ before operation to $781 \mathrm{nmol} / \mathrm{l}$ postoperatively. ${ }^{18}$ When the stress response was reduced by the administration of analgesia, the infants were more stable postoperatively.

While the stress response may be beneficial in the short term there are some drawbacks. In the absence of hypovolaemia stress induces unwanted hypertension associated with the breakdown of protein and a negative nitrogen balance. ${ }^{19}$ Transcutaneous oxygen measurements have shown that many core orientated stimuli given to preterm infants produce a fall in $\mathrm{pO}_{2} .{ }^{20}$ The results of the present study indicate that infants being given intensive medical treatment are even more stressed than those who have had surgery. Painful procedures liable to cause stress, such as insertion of venous cannulae and arterial stabs, perhaps should be accompanied by better sedation and the provision of appropriate analgesia for ill preterm infants.

\footnotetext{
References

' Murphy JF, Joyce B, Dyas J, Hughes IA. Plasma 17hydroxyprogesterone concentrations in ill newborn infants. Arch Dis Child 1983;58:532-4.

2 Thomas S, Murphy JF, Dyas J, Ryalls M, Hughes IA. Response to ACTH in the newborn. Arch Dis Child 1986;61:57-60.

${ }^{3}$ Gutai J, George R, Kaeff S, Bacon GE. Adrenal response to
} 


\section{Hughes, Murphy, Dyas, Robinson, Riad-Fahmy, and Hughes}

physical stress and the effect of adrenocorticotrophic hormone in newborn infants. $J$ Pediatr 1972;81:719-25.

4 Reynolds JW. Total serum corticoid and cortisol levels in premature infants with respiratory distress syndrome. Pediatrics 1973;51:884-90.

${ }^{5}$ Kraiem Z, Kahana L, Elias V, Ghersin S, Sheinfeld M. Radioimmunoassay of cortisol in blood collected on filter paper. Clin Chem 1980;26:1916.

${ }^{6}$ Riordan FAI, Wood PJ, Wakelin K, Betts P, Clayton BE. Blood spot $17 \alpha$-hydroxyprogesterone radioimmunoassay for diagnosis of congenital adrenal hyperplasia and home monitoring of corticosteroid replacement therapy. Lancet 1984;i:708-11.

7 Robinson JA, Dyas J, Hughes IA, Riad-Fahmy D. Radioimmunoassay of blood spot $17 \alpha$-hydroxyprogesterone in the management of congenital adrenal hyperplasia. Ann Clin Biochem 1987;24:58-65.

${ }^{8}$ Ballard J, Kazmaier K, Driver M. A simplified assessment of gestational age. Pediatr Res 1977;11:374.

$y$ Stevens JF. Plasma cortisol levels in the neonatal period. Arch Dis Child 1970;45:592-4.

${ }^{10}$ Winter JSD. The adrenal cortex in the fetus and neonate. In: Anderson DC, Winter JSD, eds. Adrenal cortex. London: Butterworth, 1985:32-56.

1 Kraiem Z, Sack J, Brish M. Serum cortisol levels: the first 10 days in full-term and preterm infants. Isr J Med Sci 1985;21: $170-2$.

12 Schapiro S, Geller E, Eiduson S. Neonatal adrenal cortical response to stress and vasopressin. Proc Soc Exp Biol Med 1962;109:937-41.

13 Diez JA, Sze PY, Ginsburg BE. Postnatal development of mouse plasma and brain corticosterone levels: new findings contingent upon the use of a competitive protein binding assay. Endocrinology 1976;98:1434-42.

${ }^{14}$ Corbier P, Roffi J. Pituitary adrenocortical response to stress during the first day of postnatal life in the rat. Biol Neonate 1978:34:105-11.

15 Plumpton ES, Besser GM, Cole PV. Corticosteroid treatment and surgery. Anaesthesia 1969;24:3-11.

${ }^{16}$ Forest MG. Age-related response of plasma testosterone, androstenedione and cortisol to adrenocorticotrophin in infants, children and adults. J Clin Endocrinol Metab 1978;47:931-7.

17 Hahn H. Adaptationsmechanismen der nebennierenrinde. Munich: Ludwig Maximilians University 1976. (M D thesis). $116 \mathrm{pp}$.

18 Anand KJS, Yacoub MH, Brown MJ, Sippell WG, AynsleyGreen A. Endocrine and metabolic regulation in term neonates undergoing cardiac surgery with cardiopulmonary bypass. Pediatr Res 1985;19:628.

19 Ellis FR, Humphrey DE. Clinical aspects of endocrine and metabolic changes relating to anaesthesia and surgery. In: Watkins J, Salo M, eds. Trauma, stress and immunity in anaesthesia and surgery. London: Butterworth, 1982:189-208.

20) Danford DA, Miske S, Headley J, Nelson RM. Effects of routine core procedures on transcutaneous oxygen in neonates: a quantitative approach. Arch Dis Child 1983;58:20-3.

Correspondence to Dr IA Hughes, Department of Child Health, University of Wales College of Medicine, Heath Park, Cardiff CF4 $4 \mathrm{XN}$.

Received 3 May 1987 